\title{
DYNAMIC RESPONSE OF EXISTING STEEL FRAMES WITH MASONRY INFILLS UNDER MULTIPLE EARTHQUAKES
}

\author{
Luigi Di Sarno ${ }^{1}$, Jing-Ren Wu ${ }^{1}$, Fernando Gutiérrez-Urzúa ${ }^{2}$, Fabio Freddi ${ }^{2}$, Mario \\ D'Aniello ${ }^{3}$, Oh-Sung Kwon ${ }^{4}$, Stathis Bousias ${ }^{5}$ and Matjaž Dolšek ${ }^{6}$ \\ ${ }^{1}$ Department of Civil Engineering and Industrial Design, University of Liverpool \\ The Quadrangle, Brownlow Hill, Liverpool, United Kingdom \\ e-mail: \{luigi.di-sarno,jingren.wu\}@liverpool.ac.uk \\ ${ }^{2}$ Department of Civil, Environment and Geomatic Engineering, University College London \\ Gower Street, London, United Kingdom \\ \{f.freddi,f.urzua\}@ucl.ac.uk \\ ${ }^{3}$ Department of Structures for Engineering and Architecture, University of Naples Federico II \\ Corso Umberto I 40, Naples, Italy \\ mdaniel@unina.it \\ ${ }^{4}$ Department of Civil and Mineral Engineering, University of Toronto \\ 27 King's College Cir, ON M5S, Toronto, Canada \\ os.kown@utoronto.ca \\ ${ }^{5}$ Structures Laboratory (STRULAB), Civil Engineering Department, University of Patras \\ University Campus, 26504 Rio Achaia, Patras, Greece \\ sbousias@upatras.gr \\ ${ }^{6}$ Faculty of Civil and Geodetic Engineering, University of Ljubljana \\ Kongresni trg 12, 1000, Ljubljana, Slovenia \\ matjaz.dolsek@fgg.uni-lj.si
}

Keywords: Existing steel frames, Masonry infills, Multiple earthquakes, Dynamic analysis

Abstract. Existing steel moment-resisting frames in several seismic regions worldwide are often characterised by high vulnerability to earthquakes due to insufficient local and/or global ductility. Therefore, it is of paramount importance to assess their response under strong motions and provide cost-effective retrofitting remedies. However, the current code-based assessment framework utilized in Europe for assessing existing structures is inadequate and requires improvement, especially to account for the contribution of masonry infills as they significantly influence the seismic response of steel buildings. To this end, the H2020-INFRAIA-SERA project HITFRAMES (i.e., HybrId Testing of an Existing Steel Frame with Infills under Multiple EarthquakeS) aims at experimental evaluation of a case study building representative of nonseismically designed European steel frames. This paper presents the dynamic response analyses of the case study building and serves as a theoretical prediction of the experimental results 
for HITFRAMES. The case study building is analysed as a bare, an infilled and a retrofitted frame with buckling restrained braces (BRBs), respectively. It is subjected to the natural seismic sequence recorded during the 2016-2017 Central Italy earthquakes. The modal properties of the case study building are determined first, followed by the investigation of its non-linear dynamic response. The dynamic tests are performed with the earthquake records scaled to different intensity levels to simulate the structural performance under different limit states according to Eurocode 8-Part 3. The impact of masonry infills and BRB-retrofit is also investigated by comparing the response of models with different configurations. It can be concluded that appropriately-designed BRBs are effective in protecting steel frames from experiencing critical damage during earthquakes and reducing significantly the transient and residual drift. 


\section{INTRODUCTION}

It has now been widely recognised in modern seismic codes that the inelastic behaviour of structural systems plays an important role in their seismic response during earthquakes. However, numerous existing buildings in current earthquake-prone areas in Europe were constructed before the seismic provisions of Eurocode 8 or complied with low seismic resistance. Such buildings are often characterised by insufficient ductile design and low energy dissipation capacity, hence high vulnerability to earthquakes. Therefore, it is necessary to develop an advanced framework of the assessment of existing buildings, which further leads to an optimised retrofit solution.

Previous research has been done on the seismic performance of existing steel frames [1][2][3], which is a popular topic in the context of assessing existing buildings. Typical damage on existing steel frames after strong ground motions include significant yielding on columns, especially at beam-column connections, cracks or partial collapse of cladding and masonry infills, and large residual drifts that leave the building little residual strength to carry vertical loading. It is also found that the seismic performance of the steel building was greatly affected by the presence of the infill walls. Existing research in literature shows that masonry infills considerably increase the lateral stiffness and strength of buildings and at the same time cause much higher localised stress at the contact areas between the corners of infills and the framed system, normally the beam-column connections [4][5][6]. Moreover, the presence of infills may lead to even higher vulnerability of existing building to collapse in moderate and strong earthquakes, as it increases the possibility of soft storey mechanisms at lower floors, eventually resulting in the collapse of the entire building.

However, despite large effort has been put into the study of seismic behaviour of infilled structures, most research was carried out on reinforced concrete buildings and there is a lack of studies on steel building with infills. Besides, most of the popular numerical models of masonry infill walls (e.g. single strut model) were developed and calibrated for reinforced concrete buildings, which naturally leads to the question that whether those models of infills are appropriate in the case of steel buildings, which are usually more flexible compared to reinforced concrete buildings. To this end, the H2020-SERA project 'Hybrid Testing of an Existing Steel Frame with Infills under Multiple Earthquakes' (HITFRAMES) aims at performing pseudo-dynamic tests on a typical existing steel frame model and providing insights on the seismic behaviour of existing steel building with infills. The project also involves assessment of the retrofit technique that uses buckling restrained braces (BRBs), which are efficient energy dissipation devices that are capable of withstanding both tension and compression in an almost symmetrical way [7][8][9].

This paper presents the theoretical estimation of the structural response of a two-storey steel moment-resisting frame under multiple earthquakes. The steel frame was designed to sustain only gravity loads with similar deficiencies found in the previously-mentioned steel building in Amatrice, hence is considered not safe under moderate and strong earthquakes and requires retrofit. The steel frame was modelled in OpenSees [10] as a bare, an infilled and a retrofitted frame with BRBs, respectively, so that the response with different configurations of the steel frame model can be compared. Firstly, the seismic response of the steel frame under the unscaled record of selected earthquake sequence will be investigated, so that some moderate damage are expected without global collapse. Then a scaling factor of 3.0 will be applied to the record of earthquake sequence in order to cause more significant damage on the structure. This paper also presents comparison of the peak and residual inter-storey drifts of different models to investigate the effects of infills and effectiveness of the BRBs. Besides, to predict the performance of the steel frame during laboratory tests and to assess the capability of the designed 
BRB system, i.e. to what extent it can protect the steel frame and masonry infills and improve the overall resistance of the steel building to strong earthquakes, the behaviour of columns, masonry infills and BRBs will be examined individually.

Apart from the time history analysis, pushover analysis has already been performed according to the procedure in Eurocode 8-Part 3 [11] as a preliminary assessment of the steel frame and the results are provided in two previous papers [12][13].

\section{THE 'HITFRAMES' PROJECT}

A brief description of the HITFRAMES project will be provided here; the main aims of the project include:

- Develop reliable methods for assessing seismic performance of existing steel frames with infills under multiple earthquakes;

- Develop appropriate design procedures of BRBs that account for the contribution of masonry infills;

- Perform fragility analysis of existing steel frames with infills and retrofitted with BRBs under multiple earthquakes.

To achieve the above goals, a case study steel frame, which consists of three bays and two storeys and is referred to as the prototype frame hereafter, was designed to be a representative of existing steel buildings. The steel frame was designed for gravity loadings only and is characterised by weak column-strong beam seismic behaviour and soft storey mechanism. Then a two-storey one-bay sub-structure of the prototype frame was scaled down by a factor of 0.75 and was tested in the Structures Lab of University of Patras, Greece. The scaled sub-structure is referred to as the test frame hereafter.

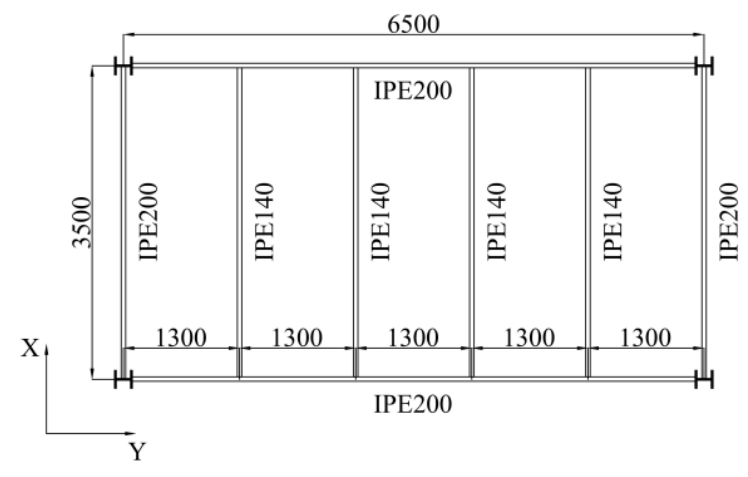

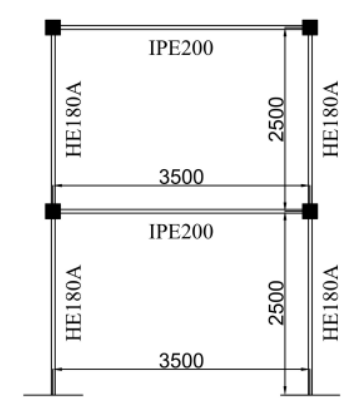

Bare frame

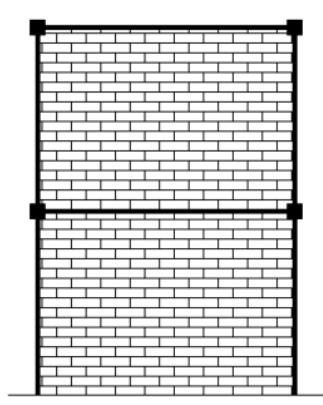

Infilled frame

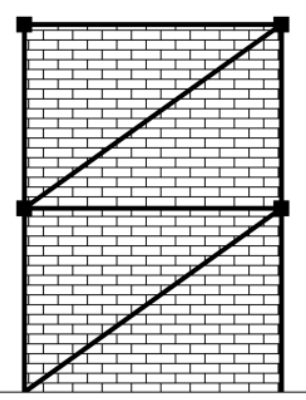

Retrofitted frame

Figure 1: Plan view (top) and side view (bottom) of the test frame with different configurations (unit: $\mathrm{mm}$ ).

The geometric properties of the test frame are provided in Figure 1. The steel profiles after scaling are IPE200, IPE140 and HE180A respectively for external beams, internal beams and columns. The steel grade is $\mathrm{S} 355\left(\mathrm{f}_{\mathrm{y}}=355 \mathrm{MPa}\right)$ for all beams and columns. Besides, the 
composite slab consists of $250 \mathrm{~mm}$-thick concrete slab poured on $1.25 \mathrm{~mm}$-thick corrugated steel sheet (SYMDECK 73). Furthermore, all external beams are connected to columns through full penetration welding, and fully rigid beam column connections are considered in this study. It is worth noting that stiffeners were placed at all beam-column connections and column base connections. Figure 2 demonstrates the position of stiffeners. Finally, the BRB consists of a BRAD damper and an elastic steel bracing, which are connected in series to each other. The BRAD damper has a hysteretic behaviour with an ultimate strength of $210 \mathrm{kN}$ at $20 \mathrm{~mm}$ displacement. The BRB will be installed externally to the framed structure and attached to the flange of columns with specially designed connection systems.
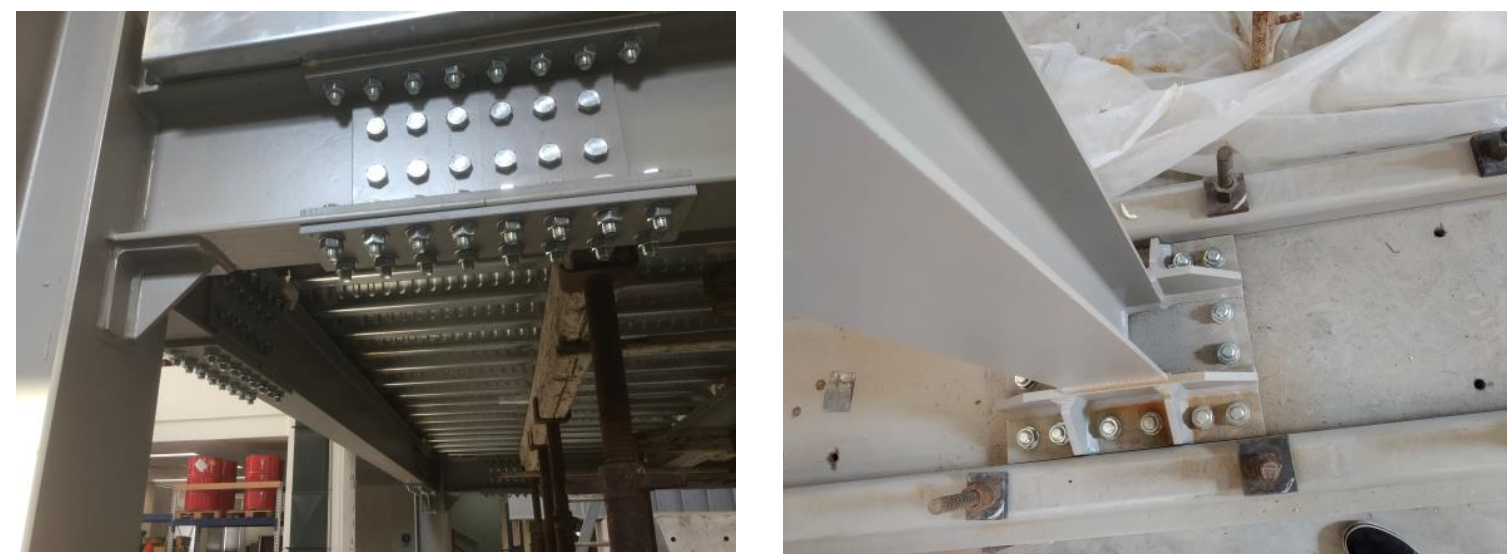

Figure 2: Stiffeners at beam column connection and column base.

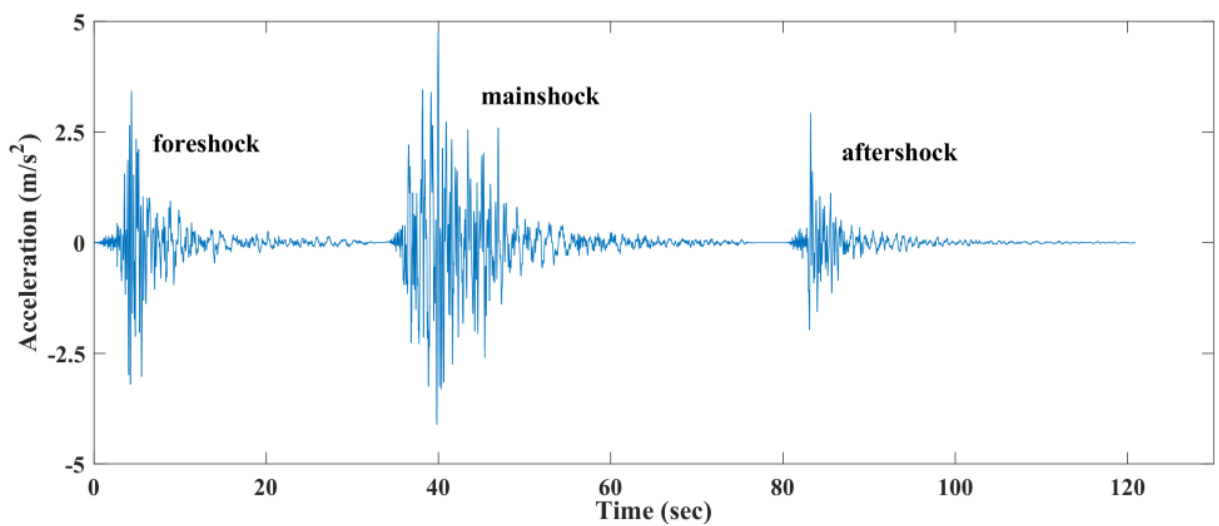

Figure 3: Acceleration history of the selected ground motion sequence.

\begin{tabular}{ccccc}
\hline Event & Date & $\mathrm{M}_{\mathrm{w}}$ & $\mathrm{R}_{\text {epi }}(\mathrm{km})$ & $\mathrm{PGA}$ \\
\hline foreshock & $24 / 08 / 2016$ & 6.0 & 15.3 & 0.35 \\
mainshock & $30 / 10 / 2016$ & 6.5 & 4.6 & 0.48 \\
aftershock & $26 / 10 / 2016$ & 5.4 & 9.4 & 0.30 \\
\hline
\end{tabular}

Table 1: Summary of records of the selected earthquake sequence used in this study.

To facilitate the tests in laboratory, a series of earthquakes records have been selected to form an earthquake sequence. Figure 3 shows the acceleration history of the earthquake sequence, which includes a foreshock with peak ground acceleration (PGA) of $0.35 \mathrm{~g}$, a mainshock with PGA of $0.48 \mathrm{~g}$ and an aftershock with PGA of $0.30 \mathrm{~g}$. Their information is also summarised 
in Table 1. Those records are able to reflect the moderate-to-high seismicity in some areas of the Southern Europe based on their PGAs.

\section{NUMERICAL MODELLING IN OPENSEES}

Similar to what has been done in [13], the test steel frame was built in the finite element software OpenSees [7] considering three different configurations:

- Case A: bare frame (only beams and columns are included)

- Case B: infilled frame (bare frame + masonry infills)

- Case C: retrofitted frame (bare frame + masonry infills + BRBs)

For finite element modelling of the test frame, beams and columns are modelled with lumped and distributed plasticity, respectively. Each beam consists of an elastic element with modulus of elasticity $210 \mathrm{GPa}$, plus two end plastic hinges to represent the lumped plasticity. The property of the plastic hinges is determined based on the moment-rotation relationship suggested in [14]. The plastic hinges are further modified based on the proposal in [15] to ensure more accurate overall lateral stiffness. The property of beam plastic hinges is shown in Figure 4. It should be noted that only the beam plastic hinges in $\mathrm{X}$ direction (test direction) are considered in the model. On the other hand, all columns are modelled using fibre-elements with ten integration points. The columns have the same modulus of elasticity as the elastic elements in beams and with $2 \%$ post-yield strain hardening.
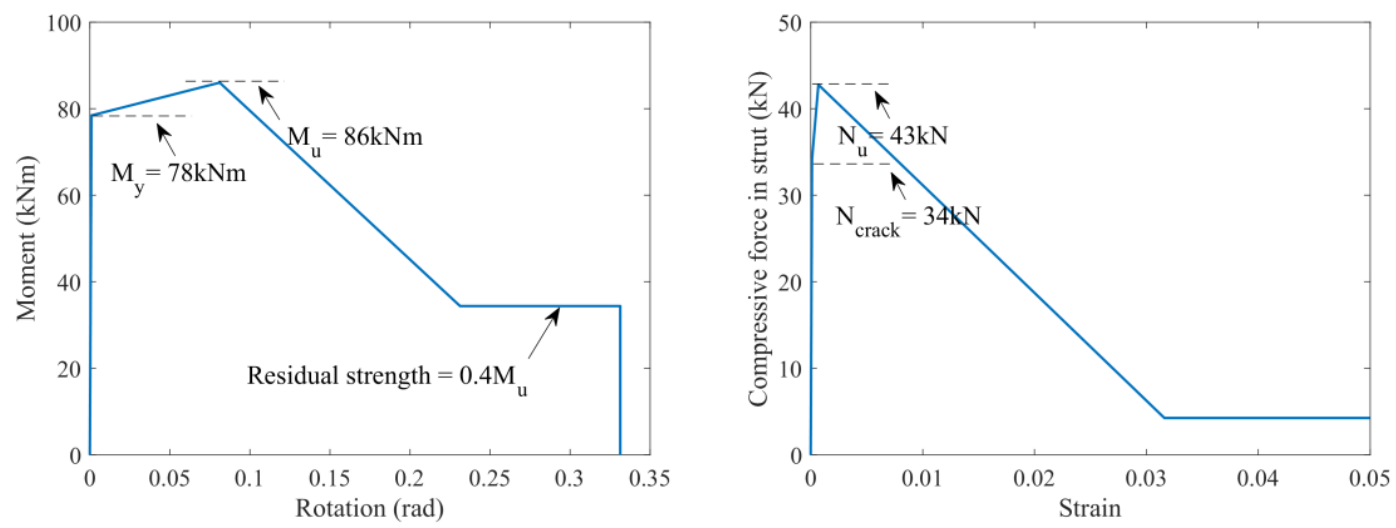

Figure 4: Backbone curve of the beam plastic hinges (left) and the infill struts (right).

In terms of the modelling of masonry infills, there are several alternatives available in literature ([4][5][16][17][18] among others), however, most of the widely-used models were developed for reinforced concrete buildings and their reliability of being applied in steel frames, which are normally more flexible than concrete buildings, is not examined. In this case study, the single-strut model adapted from the one used by Mohammad [16] and Liberatore and Decanini [18] is temporally adopted, and its property will be adjusted in the future according to the test results. A detailed discussion on the modelling of infills is provided in [13]. Figure 4 shows the backbone curve of infill struts in the compressive range, while in the tensile range, zero-strength is assumed.

\section{MODAL ANALYSIS}

Modal analyses are firstly performed on all the three cases in the X direction (see Figure 1). Table 2 summarises the periods and associated mode shapes and modal masses of the first and second mode. By comparing the results from Case A and B, it is clear that both the fundamental and second periods are decreased by more than $80 \%$ due to the presence of infills, which 
considerably reduces the natural periods by contributing significantly to the lateral stiffness. In terms of the effective mass in each mode, the infills slightly increase the modal mass of the first mode and consequently decrease the mass participated in the second mode.

\begin{tabular}{c|ccc|ccc}
\hline \multirow{2}{*}{ Case } & \multicolumn{3}{|c|}{$1^{\text {st }}$ mode } & \multicolumn{3}{c}{$2^{\text {nd }}$ mode } \\
\cline { 2 - 7 } & $\begin{array}{c}\text { period } \\
(\mathrm{sec})\end{array}$ & $\begin{array}{c}\text { mode } \\
\text { shape }\end{array}$ & $\begin{array}{c}\text { modal } \\
\text { mass }\end{array}$ & $\begin{array}{c}\text { period } \\
(\mathrm{sec})\end{array}$ & $\begin{array}{c}\text { mode } \\
\text { shape }\end{array}$ & $\begin{array}{c}\text { modal } \\
\text { mass }\end{array}$ \\
\hline Case A & 0.71 & $\begin{array}{c}0.4552 \\
1.000\end{array}$ & $87.1 \%$ & 0.25 & $\begin{array}{c}-1.8674 \\
1.0000\end{array}$ & $12.9 \%$ \\
\hline Case B & 0.12 & 0.5644 & $92.5 \%$ & 0.05 & -1.5043 & $7.5 \%$ \\
& $(-83 \%)$ & 1.000 & $(+6 \%)$ & $(-82 \%)$ & 1.000 & $(-42 \%)$ \\
\hline Case C & 0.12 & 0.5585 & $92.3 \%$ & 0.05 & -1.5224 & $7.7 \%$ \\
& $(-83 \%)$ & 1.000 & $(+6 \%)$ & $(-82 \%)$ & 1.000 & $(-40 \%)$ \\
\hline
\end{tabular}

Table 2: Modal properties of the case study steel frame in the test direction.

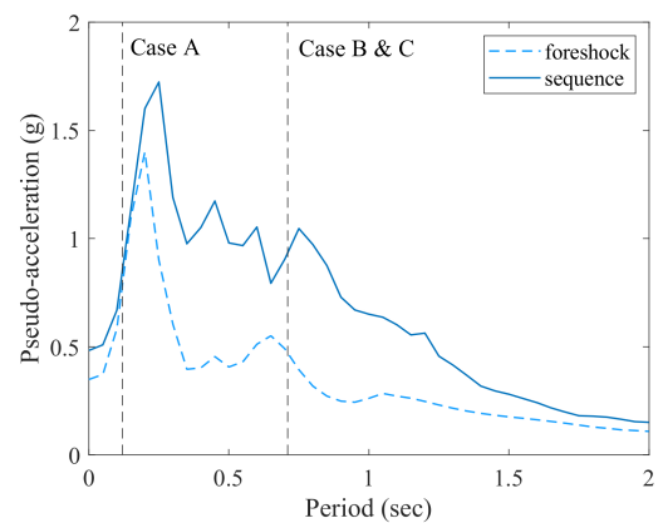

Figure 5: Elastic response spectrum of the foreshock and entire sequence in Table 1.
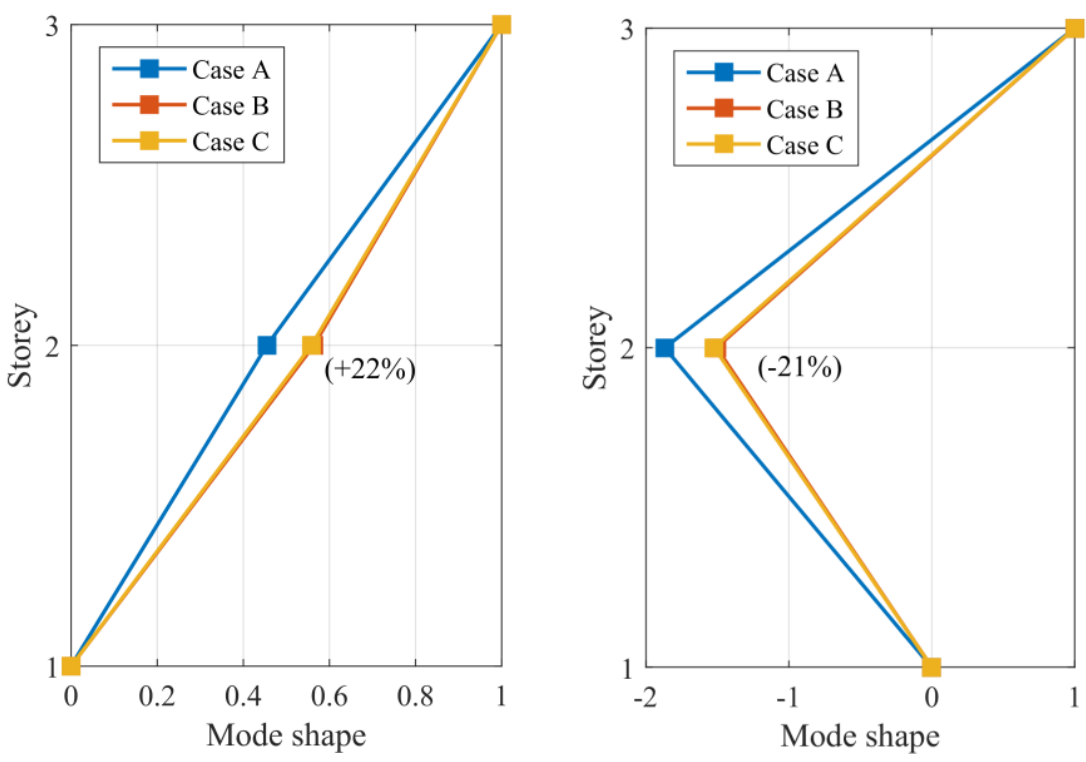

Figure 6: Normalised mode shape for the first mode (left) and the second mode (right). 
Figure 5 shows the elastic response spectrum of the foreshock and entire sequence selected in Table 1. It is found that the spectral acceleration with respect to the entire sequence is much higher than the one associated with the foreshock, except in the range of period from 0.1 to 0.15 sec, where small differences between the two spectra are observed. It should be noted that the fundamental periods of the infilled and retrofitted frame are within the above range. However, when the infilled frame is damaged, its natural periods will be longer, hence will experience higher seismic loading during the whole sequence than during the foreshock only.

Figure 6 shows the normalised mode shape of the first and second mode from all three cases. Since in all cases the fundamental mode dominates the structural behaviour, it is evident that the infilled frame is more likely to possess the soft storey mechanism as the infills will concentrate the deformation to the lower storey in this case. By comparing Case B and C, it is found that attaching BRBs to the test frame barely affects its modal properties at the initial state. However, as found in [13], the infilled frame in Case B may not able to maintain its initial modal properties during earthquakes and its natural periods and mode shapes may experience great changes due to the failure of masonry infills.

\section{TIME HISTORY ANALYSIS}

This section presents the results of time history analysis performed on the finite element model of the test frame. The inter-storey drifts and residual drifts of different models will be compared to investigate the effects of infills and effectiveness of the BRBs. The behaviour of columns, masonry infills and BRBs will also be presented individually in the following sections. The assessment of the test frame will be carried out with the help of inter-storey drift limits in Table 3 proposed by ASCE41-06 [19], which are adapted to comply to the limit states in EC83 [11], i.e. Damage Limitation (DL), Significant Damage (SD) and Near Collapse (NC) limit state.

\begin{tabular}{ccc}
\hline $\mathrm{DL}$ & $\mathrm{SD}$ & $\mathrm{NC}$ \\
\hline $0.7 \%$ & $2.5 \%$ & $5.0 \%$ \\
\hline
\end{tabular}

Table 3: Inter-storey drift ratio limits adapted to the limit states in EC8-3.

\subsection{Structural response under unscaled earthquake sequence}

The response of the test frame with the three different configurations are compared in Figure 7 in terms of their first and second storey drift. The effects of infills is evident as the amplitudes in Figure 7 are reduced by more than 50\% when the infills are present. It is also found that the current zero-acceleration periods, which were introduced to simulate the time interval between two earthquakes, are not long enough for the bare frame to rest due to the large vibration amplitudes and relatively low damping ratio of steel frames (3\% damping assumed for the test frame). However, it is adequate to calm down the infilled and retrofitted frame, therefore, quite long periods of low-amplitude vibration are expected when the infilled frame is tested in the laboratory.

By comparing the first and second floor drifts, it can be concluded from Figure 7 that for the bare frame, the roof displacement are equally distributed to the first and second storey, which is consistent with its first mode shape in Figure 6. For the infilled and retrofitted frame, the drift of the second floor is considerably smaller than that of the first floor, indicating concentration of lateral displacement on the first floor (soft-storey mechanism), where more evident damage may be observed. Besides, Figure 7 also shows that the bare frame experienced large residual drift on both floors after the second earthquake, which has the largest PGA as indicated in Table 
1. On the other hand, the residual drifts of the infilled and retrofitted frame are very small and can be neglected. The peak and residual drifts are summarised in Table 4. Finally, it seems that the BRBs do not have significant effects on the overall structural behaviour when they are installed on the infilled frame, although it tends to slightly reduce the storey drift. Since it is found from previous discussion that the first-floor slab (also the top of ground floor) suffers the critical lateral displacement in Case B and $\mathrm{C}$, the response of columns, infills and BRBs on the ground floor will be presented hereafter.
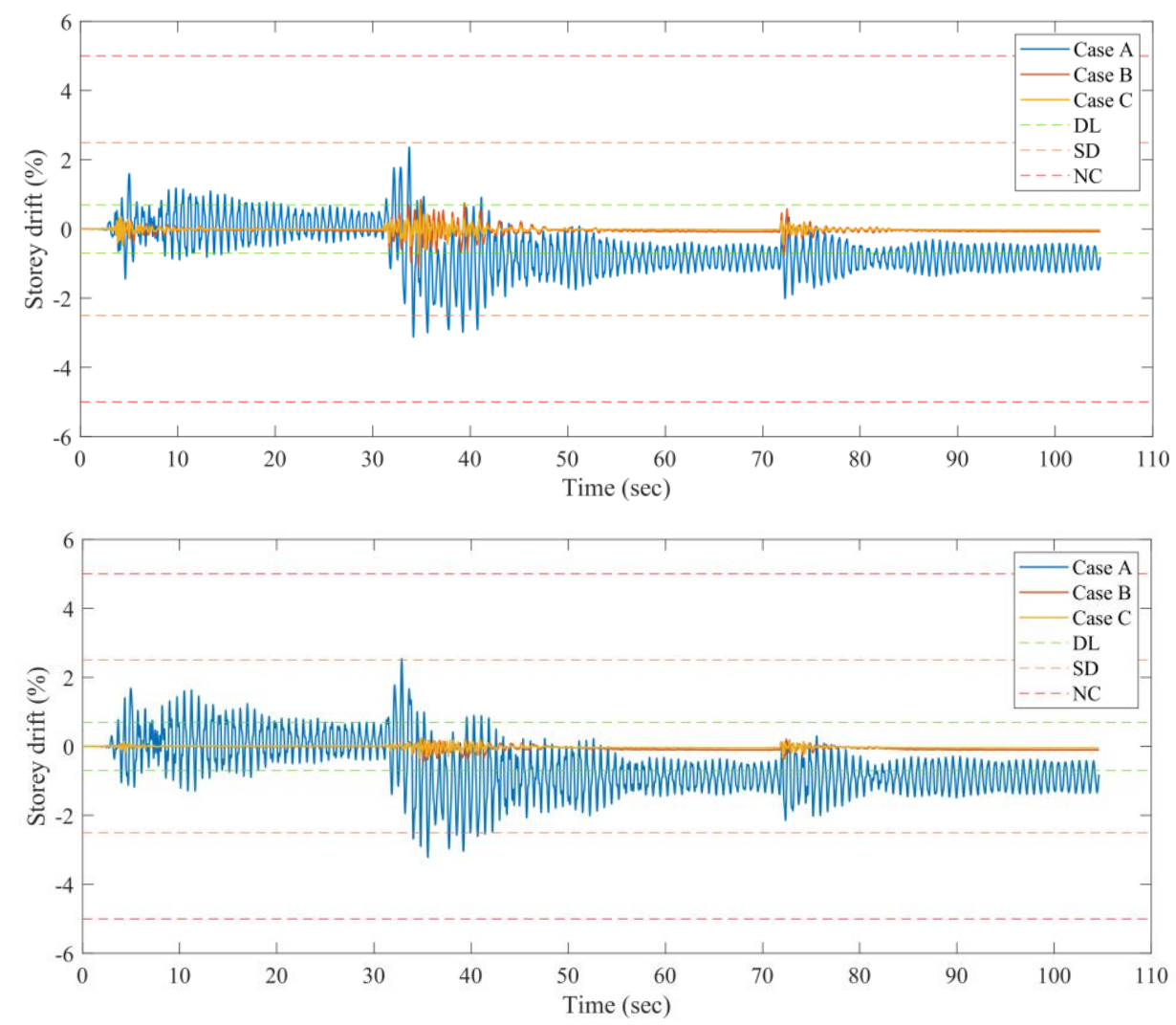

Figure 7: Response of the case study frame in terms of the first (top) and second (bottom) floor drift under unscaled earthquake sequence.

\begin{tabular}{llcccccc}
\hline & & \multicolumn{2}{c}{ GM1 } & \multicolumn{2}{c}{ GM2 } & \multicolumn{2}{c}{ GM3 } \\
\cline { 3 - 8 } & & Peak & Residual & Peak & Residual & Peak & Residual \\
\hline \multirow{2}{*}{ Case A } & 1F & 1.6 & 0.13 & 3.1 & 0.83 & 2.0 & 0.84 \\
& 2F & 1.7 & 0.15 & 3.2 & 0.89 & 2.1 & 0.88 \\
\hline \multirow{2}{*}{ Case B } & 1F & 0.5 & 0.05 & 1.1 & 0.08 & 0.8 & 0.07 \\
& 2F & 0.1 & 0.00 & 0.4 & 0.11 & 0.4 & 0.11 \\
\hline \multirow{2}{*}{ Case C } & 1F & 0.5 & 0.05 & 0.9 & 0.07 & 0.5 & 0.08 \\
& 2F & 0.2 & 0.01 & 0.2 & 0.03 & 0.1 & 0.03 \\
\hline
\end{tabular}

Table 4 Peak and residual drifts $(\%)$ of the case study frame under unscaled earthquake sequence.

Figure 8 presents the moment-rotation behaviour at the base of columns on the two sides of the test frame. It is found that the columns in the bare frame reached a maximum rotation of more than twice the yield rotation $\theta_{y}$, while in the infilled and retrofitted frame, the maximum column base rotation was around $\theta_{y}$ and $0.5 \theta_{y}$, respectively. It is also noticed that the BRB 
caused slight differences between the behaviour of columns on its two sides, probably due to the higher axial load in the left-side column in Figure 1 as a result of the orientation of the BRB. Furthermore, the response of masonry infills with and without BRBs is presented in Figure 9, which shows the axial force-displacement diagram of the two struts forming the same masonry wall but in opposite directions. As expected, the designed BRBs reduced the displacement of masonry infills both in tension and in compression, however, it failed to protect the infills from cracking and experiencing degrading of stiffness. Figure 10 shows the behaviour of the BRBs adopted for the retrofit of the case study frame. It is clearly demonstrated that the BRBs are only slightly yield and have not fully developed their full post-yield strength and displacement capacity.

It can be concluded that in the case of unscaled earthquake sequence, the BRBs were barely activated, therefore, they only contributed to the lateral stiffness and strength of the structure and hardly improved the overall energy dissipation capability. The columns were well protected from yielding by infills and BRBs, and the structure were verified safe at significant damage limit state according to Table 3, and the retrofitted frame was close to satisfying the damage limitation limit state.
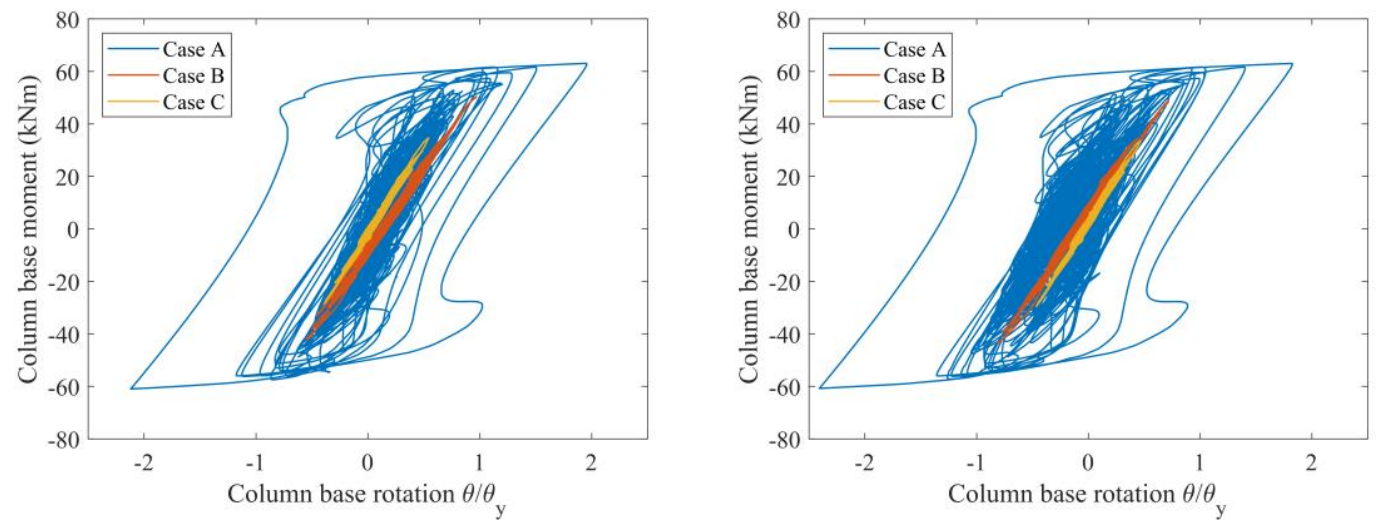

Figure 8: Moment-rotation response of ground floor columns in Figure 2.
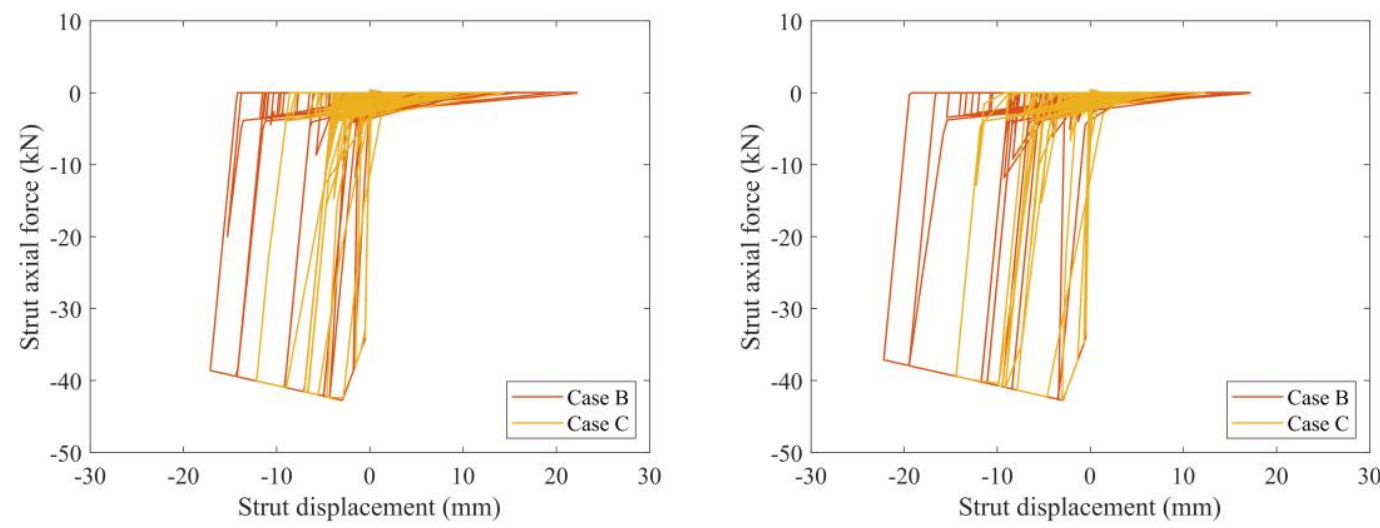

Figure 9: Force-displacement diagram of masonry infill struts on the ground floor in opposite directions. 


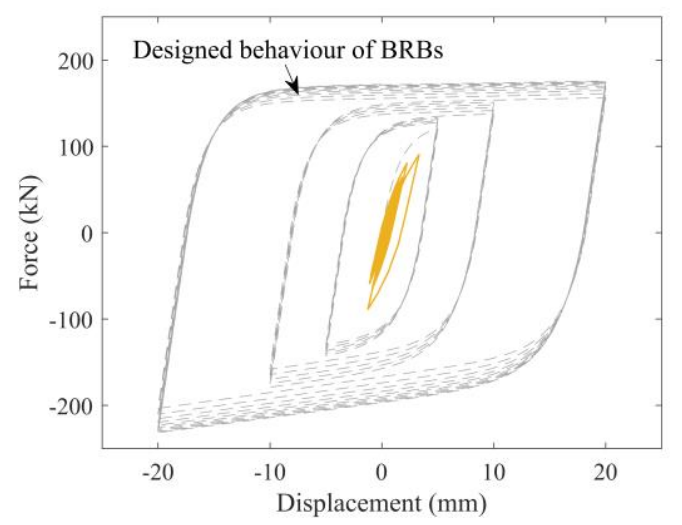

Figure 10: Cyclic behaviour of BRB in Case C.

\subsection{Structural response under scaled earthquake sequence}

The results obtained with the scaled earthquake sequence are presented in this section in a similar manner to what have been done for the unscaled earthquake sequence. It should be noted that the bare frame in Case A were not involved in this part of assessment as it is by nature not able to survive such strong earthquakes. Generally speaking, the test frame experienced much more severe damage when it was under the scaled earthquake sequence, which meets the expectation of significantly damaging the infilled frame in the lab so that more information of the seismic behaviour of the steel frame can be collected for further study. Figure 11 shows the inter-storey drift of the frame in Case B and C. It is clear that the infilled frame experienced increasing residual drifts up to $2.4 \%$ after each earthquake on both storey when there was no protection from BRBs, and the first storey suffered a peak drift of nearly $6 \%$ during the second earthquake. Besides, it is also clearly demonstrated in Figure 11 that the BRBs in Case C effectively reduced both the peak drift of the steel frame by around $50 \%$ and in most cases reduced the residual drift by a large amount as well, as indicated in Table 5.

Figure 12 shows the response of columns. It is found that under the strong earthquakes, the columns in the infilled frame were significantly yielded and suffered large deformation at the column bases (approximately $5 \theta_{y}$ ). However, the rotation of column in the retrofitted frame was reduced to around $2 \theta_{y}$. Figure 13 and 14 shows the cyclic response of infill struts and BRBs, respectively. It can be anticipated from Figure 13 that severe damage or even partial collapse may occur on the infill walls without BRBs' protection, as one of the struts is approaching its residual strength, which is around $4 \mathrm{kN}$. However, when the BRBs were included, the infills experienced 50\% smaller peak displacement in both tension and compression, although cracks and stiffness degradation were still observed. This is not a surprise as the BRBs adopted failed to prevent the infills from cracking under the previous unscaled earthquake sequence. The behaviour of BRB in Figure 14 suggests that the BRB was activated during the earthquake sequence with a shift of equilibrium position to around $0.01 \mathrm{~mm}$. It also experienced a larger displacement than its ultimate limit, which occurred during the second earthquake component, indicating that in reality the BRB was probably unable to dissipate energy anymore after it was broken.

In conclusion, when a scaling factor of 3 was applied to the previous earthquake sequence, the BRBs on the ground floor were clearly activated and contributed to the energy dissipation capability through its cyclic behaviour. The columns were protected with maximum base rotation being reduced by more than $50 \%$, and the retrofitted frame were eventually verified safe at the near collapse limit state according to Table 3. 

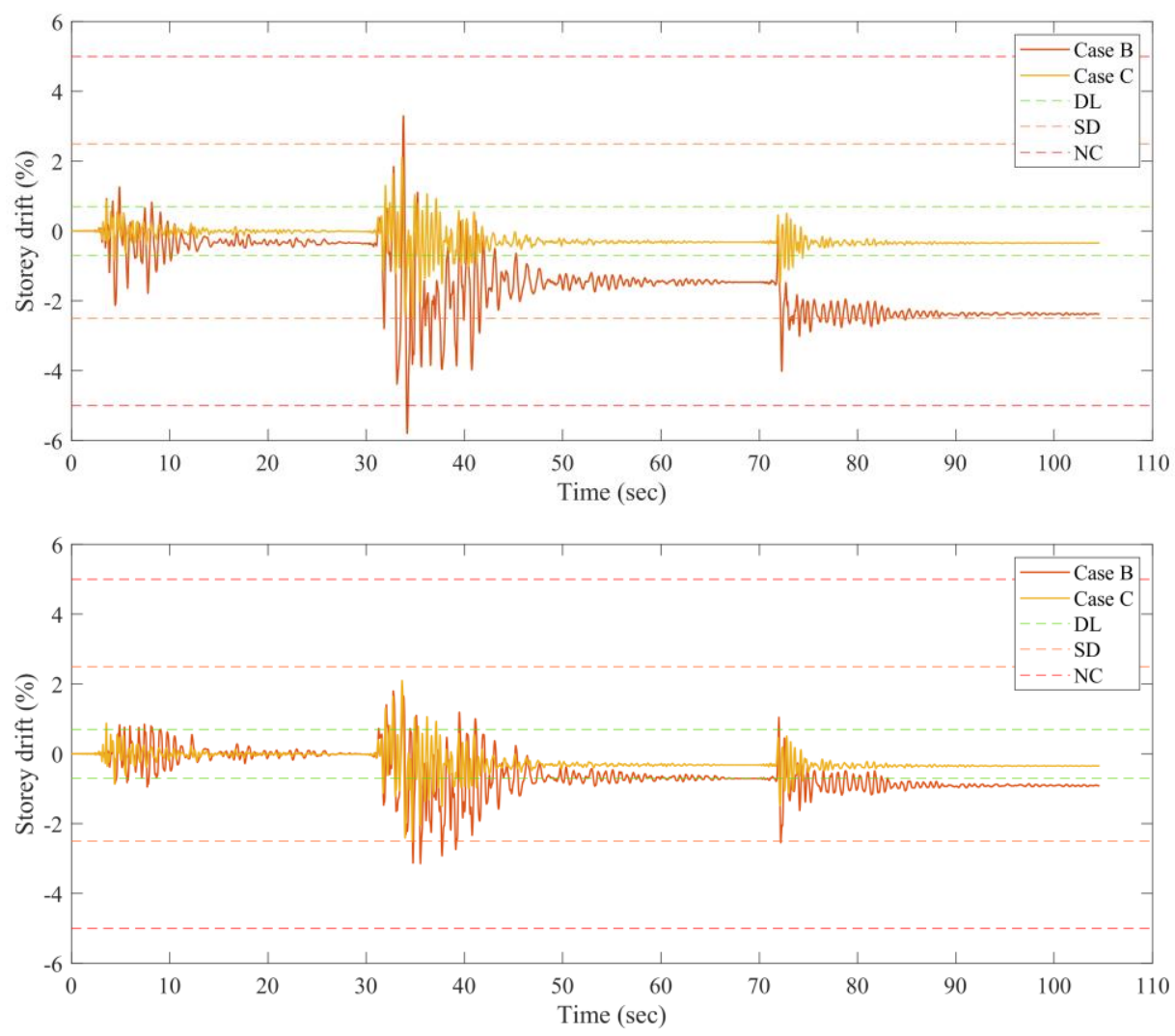

Figure 11: Response of the case study frame in terms of the first (top) and second (bottom) floor drift under scaled earthquake sequence.

\begin{tabular}{lccccccc}
\hline & & \multicolumn{2}{c}{ GM1 } & \multicolumn{2}{c}{ GM2 } & \multicolumn{2}{c}{ GM3 } \\
\cline { 3 - 7 } & & Peak & Residual & Peak & Residual & Peak & Residual \\
\hline \multirow{2}{*}{ Case B } & 1F & 2.1 & 0.35 & 5.8 & 1.47 & 4.0 & 2.38 \\
& 2F & 0.9 & 0.00 & 3.1 & 0.70 & 2.5 & 0.90 \\
\hline \multirow{2}{*}{ Case C } & $1 \mathrm{~F}$ & 0.9 & 0.01 & 2.5 & 0.32 & 1.5 & 0.34 \\
& 2F & 0.7 & 0.02 & 1.8 & 0.16 & 1.5 & 0.18 \\
\hline
\end{tabular}

Table 5: Peak and residual drifts $(\%)$ of the case study frame under scaled earthquake sequence.
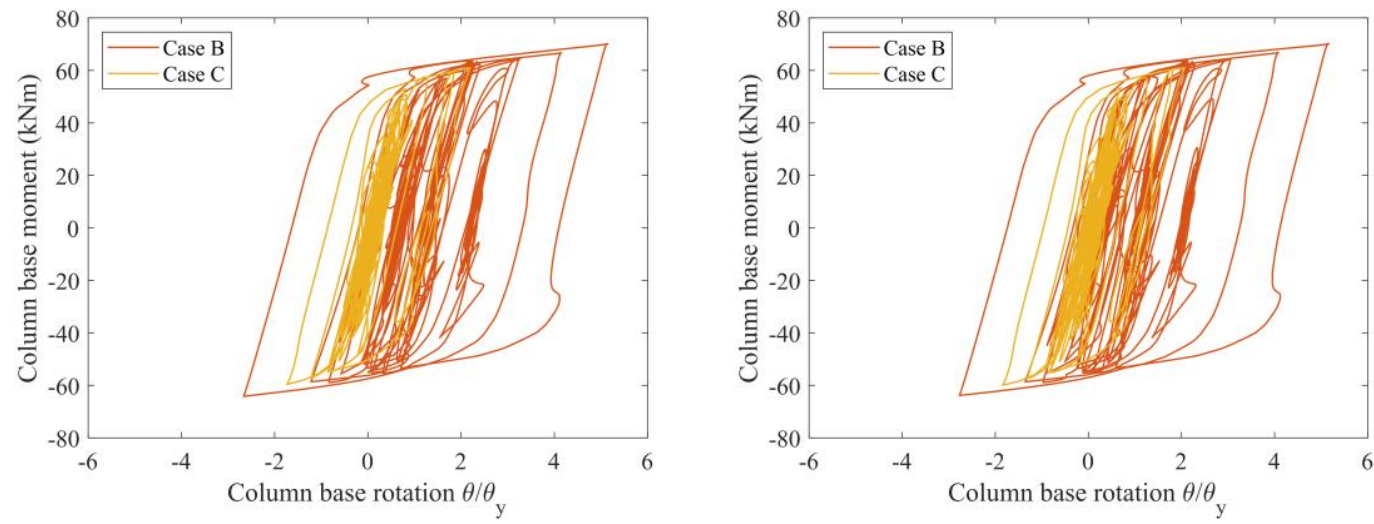

Figure 12: Moment-rotation response of ground floor columns in Figure 2. 

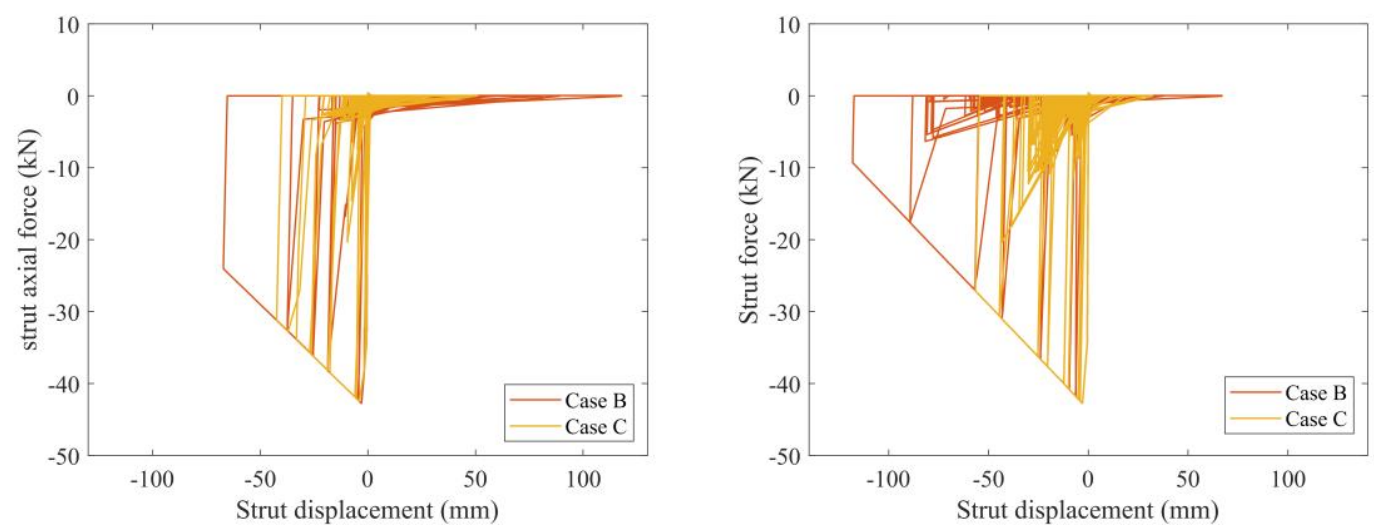

Figure 13: Force-displacement diagram of masonry infill struts on the ground floor in opposite directions.

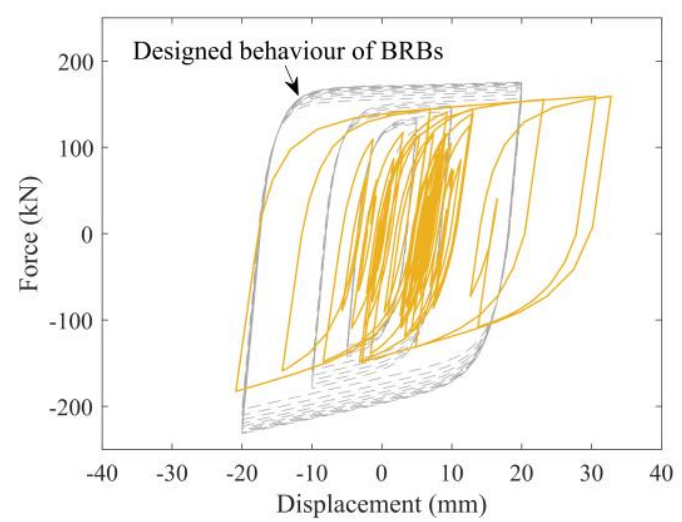

Figure 14: Cyclic behaviour of BRB in Case C.

\section{CONCLUSIONS}

This paper presented the results of preliminary dynamic analysis carried out on a 2-storey case study steel frame designed for the experimental tests of the HITFRAMES project. The steel frame was designed to be a representative of existing steel frames in Southern Europe. Dynamic analysis was performed on the steel frame in different configurations, including the bare frame, the infilled frame and the infilled frame retrofitted with BRBs. The analysis was done as a preparatory work for the experimental tests.

Three earthquakes were selected in this study to form an earthquake sequence. The unscaled record of the entire sequence was applied to the steel frame in the first part of analysis. In the second part, the record was scaled by a factor 3.0 and then applied to the steel frame. The interstorey drifts of both floors were examined as well as the response of column, masonry infills and BRBs, in order to assess the capability of the designed BRB system of protecting the steel frame and masonry infills. It is found that under the unscaled earthquake sequence record, the BRB were barely activated, although it helped reduce the deformation of both columns and masonry infills by around 50\% and eliminated yielding in columns. When the intensity of input earthquake record was increased by a factor of 3.0, it is concluded that the BRBs were significantly damaged and exceeded its maximum deformation capacity. The column base rotation was reduced by nearly $50 \%$ due to the protection of BRBs and yielding in column was considered to be minimised. This protection is also reflected by the dramatic reduction in the transient and residual drift, where the former was decreased by around $50 \%$ and the latter was reduced to a negligible level. 
A major limitation in this study is that the flexibility of beam-column connections were not accounted for in either the strong or weak axis of columns, although the column panel zones (along the strong axis) do not play an important role in this study, since the tests will be performed along the weak axis of columns. The column base connections were not considered, either. These limitations may significantly affect the results of the real tests, which will be updated in the model calibration based on the test results.

\section{ACKNOWLEDGEMENTS}

The financial support from Seismic Engineering Research Infrastructure for HITFRAMES (SERA) Project, funded within the H2020-INFRAIA-2016-2017 Framework Program of the European Commission under grant agreement No.730900 is greatly appreciated. Any opinions, findings and conclusions, or recommendations expressed in this paper are those of the authors and do not necessarily reflect those of SERA sponsors.

\section{REFERENCES}

[1] L. Di Sarno, F, Paolacci, A.G. Sextos, Seismic performance assessment of existing steel buildings: a case study, Key Engineering Materials 763, 1067-1076, 2018.

[2] L. Di Sarno, A.S. Elnashai, Bracing systems for seismic retrofitting of steel frames, Journal of Constructional Steel Research 65(2), 452-465, 2009.

[3] J. Ruiz-García, J.C. Negrete-Manriquez, Evaluation of drift demands in existing steel frames under as-recorded far-field and near-fault mainshock-aftershock seismic sequences, Engineering Structures 33(2), 621-634, 2010.

[4] M. Dolšek, P. Fajfar, The effect of masonry infills on the seismic response of a fourstorey reinforced concrete frame - a deterministic assessment, Engineering Structures 30(7), 1991-2001, 2008.

[5] G. Uva, D. Raffaele, F. Porco, A. Fiore, On the role of equivalent strut models in the seismic assessment of infilled RC buildings, Engineering Structures 42, 83-94, 2012.

[6] M. Dolšek, P. Fajfar, Simplified non-linear seismic analysis of infilled reinforced concrete frames, Earthquake engineering \& structural dynamics 34(1), 49-66, 2005.

[7] L. Di Sarno and G. Manfredi, Seismic retrofitting with buckling restrained braces: Application to an existing non-ductile RC framed building, Soil Dynamics and Earthquake Engineering 30(11), 1279-1297, 2010.

[8] L. Di Sarno and G. Manfredi, Experimental tests on full-scale RC unretrofitted frame and retrofitted with buckling restrained braces, Earthquake Engineering and Structural Dynamics 41(2), 315-333, 2012.

[9] F. Freddi, L. Ragni, E. Tubaldi and A. Dall'Asta, Probabilistic Performance Assessment of Low-Ductility RC Frames Retrofitted With Dissipative Braces, Earthquake Engineering and Structural Dynamics 42, 993-1011, 2013.

[10] S. Mazzoni, F. McKenna, M.H. Scott, G.L. Fenves, OpenSees command language manual, Pacific Earthquake Engineering Research (PEER) Centre, 264, 2006. 
[11] British Standards Institution, BS EN 1998-3:2005, Eurocode 8. Design of structures for earthquake resistance - Part 3: Assessment and retrofitting of buildings, London: BSI; 2005.

[12] L. Di Sarno, J.R. Wu, M. D’Aniello, S. Costanzo, R. Landolfo, O.S. Kwon, F. Freddi, Assessment of existing steel frames with infills under multiple earthquakes, Proceedings of COMPDYN 2019, 7th International Conference on Computational Methods in Structural Dynamics and Earthquake Engineering, 2019.

[13] L. Di Sarno, F. Gutiérrez-Urzúa, F. Freddi, M. D’Aniello, R. Landolfo, O.S. Kwon, S. Bousias, M. Dolšek, J.R. Wu, M.G. Castellano, Pseudo-dynamic testing of existing steel frames with masonry infills: assessment and retrofitting with BRBs, Proceedings of ANIDIS 2019, XVII Convegno ANIDIS - L'Ingegneria Sismica in Italia, 2019.

[14] D.G. Lignos and H. Krawinkler, Deterioration modeling of steel components in support of collapse prediction of steel moment fames under earthquake loading, Journal of structural engineering 137(11), 1291-1302, 2011.

[15] F. Zareian, and R.A. Medina, A practical method for proper modeling of structural damping in inelastic plane structural systems, Computers and structures 88(1-2), 45-53, 2010.

[16] N. Mohammad, L. Liberatore, F. Mollaioli, and S. Tesfamariam, Modelling of masonry infilled RC frames subjected to cyclic loads: State of the art review and modelling with OpenSees, Engineering Structures 150, 599-621, 2017.

[17] M.N. Fardis, and T.B. Panagiotakos, Seismic design and response of bare and masonryinfilled reinforced concrete buildings. Part II: Infilled structures, Journal of Earthquake Engineering 1(3), 475-503, 1997.

[18] L. Liberatore, and L.D. Decanini, Effect of infills on the seismic response of high-rise RC buildings designed as bare according to Eurocode 8, Ingegneria sismica 3, 7-23, 2011.

[19] American Society of Civil Engineering, ASCE41-06. Seismic rehabilitation of existing buildings, Reston, Virginia, 2005. 